\title{
Grade III injuries of the lateral ligaments of the ankle: the incidence and a simple stress test
}

\author{
C. L. MUWANGA, MARGARET HELLIER, D. N. QUINTON, \\ J. P. SLOAN AND A. F. DOVE \\ Accident and Emergency Department, University Hospital, Nottingham, England
}

\section{SUMMARY}

One hundred and seventy-five consecutive acute ankle injuries were assessed for instability. A simplified radiological anterior stress test, without anaesthesia, was used to assess instability. Nineteen patients $(11 \%)$ showed evidence of gross instability (Grade III injuries). This is recommended as a simple screening test.

\section{INTRODUCTION}

Ankle injuries are common and comprise about $4 \%$ of the workload of accident and emergency departments. About $90 \%$ of these injuries fall in the category of 'ankle sprains' with no evidence of bone injuries (Vargish et al. 1983).

Cass \& Morrey (1984) have divided these injuries into three grades depending on the severity of the injury: Grade I: mild stretch of the ligaments and no instability; Grade II: an incomplete tear of the ligaments with mild instability; and Grade III: a complete tear of the ligaments with gross instability. The reason for differentiating the three grades is because their treatment is different. Grade I and II injuries do well with conservative treatment, but Grade III require immobilisation in plaster or surgery. Delayed repair or reconstructive surgery is offered to those with chronic instability symptoms (Cass \& Morrey, 1984; Evans et al., 1984; Freeman, 1965).

A variety of sophisticated tests have been described to distinguish between Grade I and II, and Grade III injuries. These include: arthrography (Bostrom et al., 1965); peroneal tenography (Black et al., 1978); inversion stress (talar tilt) (Rubin \& Witten, 1960); anterior stress (anterior drawer sign) (Glasgow et al., 1980); or a combination of

Correspondence: Mr Cyrus L. Muwanga, Senior Registrar, Accident and Emergency Department, Middlesborough General Hospital, Cleveland, England 
any of these, for example, the stress-tenogram (Evans \& Frenyo, 1979). For logistical $\frac{\mathrm{D}}{6}$ reasons, these tests cannot be done on all ankle sprains but it is notoriously difficult toz categorise ankle sprains by clinical examination. What is required, therefore, is aㅇ. simple, rapid method of radiological assessment of ankle ligament integrity which may $\underset{\overrightarrow{0}}{\overrightarrow{0}}$ be performed without medical staff being present: we describe such a test.

\section{METHOD}

Patients with ankle injuries occurring less than $24 \mathrm{~h}$ earlier were studied. They were $\stackrel{\vec{\omega}}{\vec{\omega}}$ aged between 15 and 45 years and had no evidence of a fracture after clinical and $\stackrel{\omega}{\omega}$ radiological examination.

Their ankles were assessed for ligamentous rupture using a padded wooden wedge and foot rest. The knee was flexed to relax the calf muscles. The leg was internally

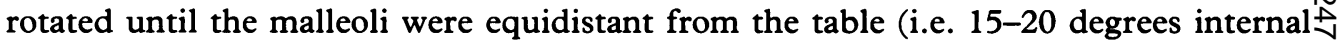
rotation) with the foot in slight inversion, thereby achieving a true lateral position. A의 moulded sand bag, weight $4.5 \mathrm{~kg}$, was placed on the lower tibia (Fig. 1); it was positioned $10 \mathrm{cms}$ from the lateral malleolus and left in position for 90 seconds to overcome the initial muscle spasm.

If $\mathrm{X}$-rays of the injured side were equivocal, then views of the uninjured side were obtained for comparison. A gap of more than $6 \mathrm{~mm}$ between the posterior tip of the tibia and the end of the articular surface of the talus or a difference of more than $3 \mathrm{~mm}$ from the uninjured side are regarded as positive and suggest a tear of the anterior talo-fibular
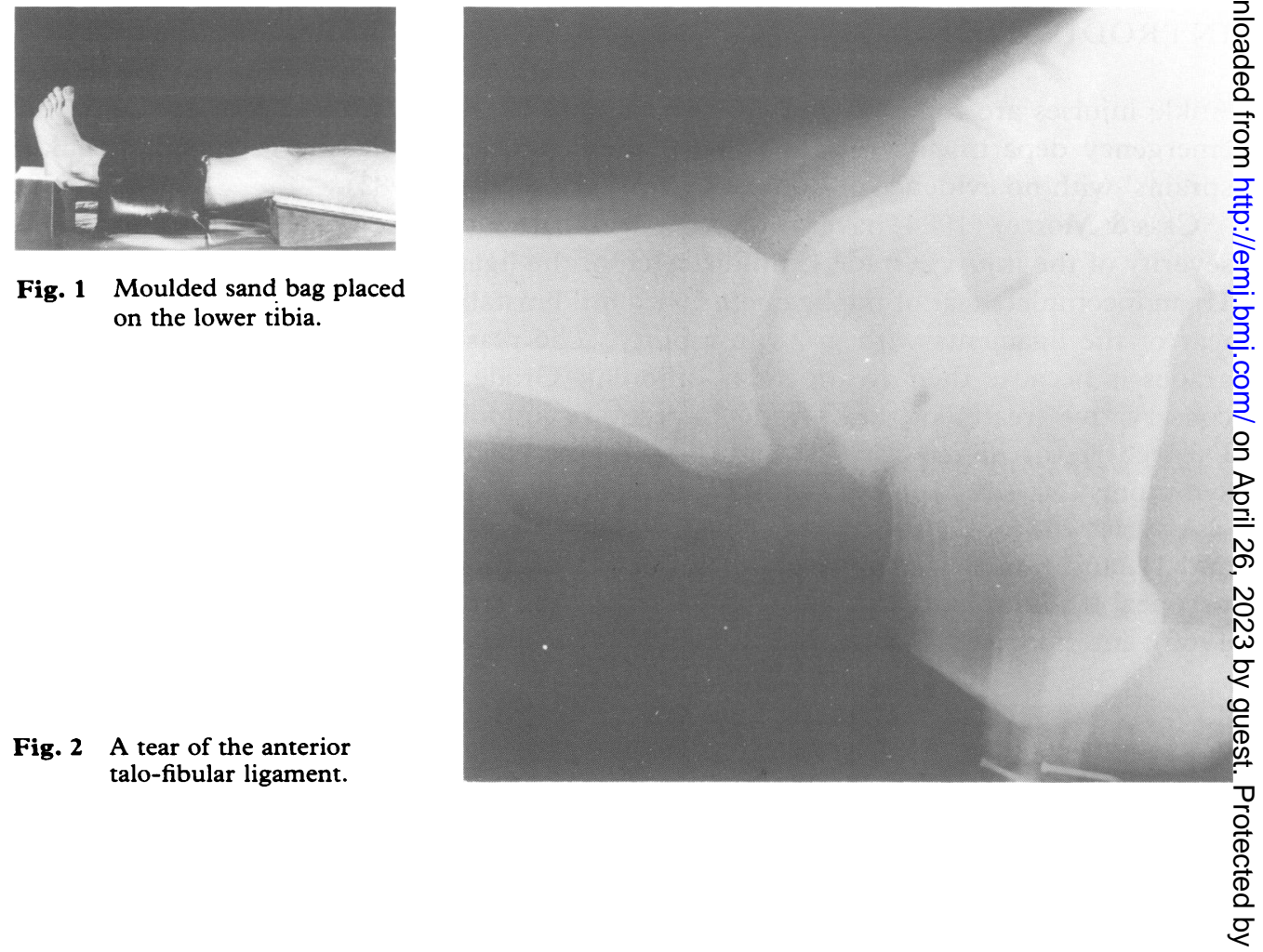

Fig. 2 A tear of the anterior talo-fibular ligament. 
ligament, with or without other associated ligaments rupture (Glasgow et al., 1980) (Fig. 2).

The study was designed so that the technique could be performed by trained radiographers with a wide range of experience.

\section{RESULTS}

In all, 206 patients were studied (Table 1): 31 (15\%) had fractures. The remaining 175 patients included 120 males and 55 females with a mean age of 25 years. Using the described technique, $19(11 \%)$ of those patients who had no fractures had a talo-tibial gap in excess of $6 \mathrm{~mm}$. The mean distance was $9 \mathrm{~mm}$ (range: 6-13 $\mathrm{mm}$ ). In the remainder, the mean distance was $4 \mathrm{~mm}$ (range: $3-5.9 \mathrm{~mm}$ ).

Table 1 Soft tissue injuries of the ankle

\begin{tabular}{llll}
\hline & Stable & Unstable & Total \\
\hline No. of patients (\%) & $164(89)$ & $19(11)$ & $175(100)$ \\
Sex & & & \\
Male & 106 & 14 & 55 \\
Female & 50 & 5 & \\
Age & & & 25 years \\
Mean & & & $15-45$ years \\
Range & & & \\
Posterior Talo- & & $9 \mathrm{~mm}$ & \\
Tibial Gap & $4 \mathrm{~mm}$ & $6-13 \mathrm{~mm}$ & \\
Mean & $3-5 \cdot 9 \mathrm{~mm}$ & & \\
Range & & 9 weeks \\
Follow-up time & 9 days & $4-17$ weeks \\
Mean & $5-14$ days & \\
Range & &
\end{tabular}

The average follow-up time in the unstable group before discharge was 9 weeks (range: 4-17 weeks). Primary surgical repair was carried out on one of two patients examined under general anaesthesia. The rest were treated conservatively with initial immobilisation in P.O.P.; on average 4 weeks (range: 3-6 weeks).

The average follow-up time in the stable group before discharge was 9 days (range: 514 days). They were treated with either Double Tubigrip, Eversion Strapping or a newly designed ankle support (Muwanga et al., 1986).

None of the investigations had to be curtailed because of pain. No technical difficulties were encountered and good radiographs were taken by all the radiographers. 


\section{DISCUSSION}

Much has been written about the treatment of ankle injuries: about $12 \%$ of patients will $\stackrel{2}{\circ}$ have fractures (Vargish et al., 1983) but the remainder present a diagnostic problem. $\mathrm{A}=$ significant number will have ligamentous rupture and, if they are not treated, af chronically unstable ankle may result.

Clinical examination can be helpful but it may be misleading because of the inexperience of the examining doctor. It is difficult to assess many ankles because of pain. Local tenderness is one of the most reliable signs in the acutely injured anklees (Brooks et al., 1981; Vargish et al., 1983).

Unlike Glasgow et al. (1980), the present authors have not used any form of anaesthesia and no physician was required to be present during the test.

The method of performing the anterior stress test described here is rapid, technically simple and painless. It is, therefore, suitable for use as a screening test.

The best way to treat Grade III injuries is still a subject for debate (Cass \& Morrey, 1984; Lightowler, 1984; Evans et al., 1984). It is agreed that they need more energetic $₫$ treatment than simple supports or early physiotherapy. It is essential, therefore, that? they are diagnosed as early as possible. It would appear unnecessary to differentiatebetween Grade I and Grade II injuries as the treatment for these two groups is the same (Cass \& Morrey, 1984).

It is neither practicable or ethical to subject all patients with acute ankle injuries to ano invasive radiological procedure if a non-invasive one is available. Our experience with a simplified anterior radiological stress test used as a screening test showed an $11 \mathscr{g}_{0} \circ$ incidence of instability. This is a high incidence, bearing in mind the limitation of the anterior stress tests (Lindstrand \& Mortensson, 1977).

One of the reasons why the treatment of severe ankle injuries is in dispute is because of the difficulty of diagnosis. It may be that the widespread use of a simple screening test will enable rational treatment of this potentially disabling injury.

\section{ACKNOWLEDGEMENTS}

We wish to thank Dr B. J. Preston, Consultant Radiologist, University Hospital, Nottingham, England, for his assistance, and the nursing staff and the radiographers in the Accident and Emergency Department, University Hospital, for their assistance.

\section{REFERENCES}

Black H. M., Brand R. L. \& Eichelberter M. R. (1978) An improved technique for the evaluation of $\mathcal{N}_{\mathrm{W}}^{N}$ Brooks S. C., Potter B. T. \& Rainey J. B. (1981) Inversion injuries of the ankle in clinical assessment and radiographic review. British Medical fournal 282, 606-7.

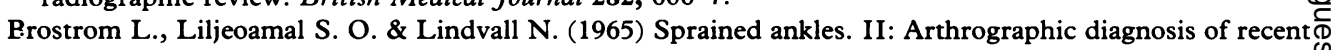
ligament ruptures. Fournal of Bone and foint Surgery 42A, 311-26. 
Cass J. R. \& Morrey B. F. (1984) Ankle instability: current concepts, diagnosis and treatment. Mayo Clinical Procedures 59, 165-70.

Evans G. A. \& Frenyo S. D. (1979) The stress-tenogram in the diagnosis of ruptures of the lateral ligament of the ankle. Fournal of Bone and foint Surgery 61-B; 347-51.

Evans G., Harcastle P. \& Frenyo A. D. (1984) Acute Rupture of the lateral ligament of the ankle: to suture or not to suture? fournal Bone and foint Surgery 66-B, 210-2.

Freeman M. A. R. (1965) Treatment of ruptures of the lateral ligament of the ankle. fournal of Bone and foint Surgery 47-B, 661-8.

Glasgow M., Jackson A. \& Jamieson A. M. (1980) Instability of the ankle after injury to the lateral ligaments. fournal of Bone and foint Surgery 62-B, 196-200.

Lightowler C. D. R. (1984) Injuries to the lateral ligament of the ankle. British Medical fournal 289, 1247.

Lindstrand A. \& Mortensson W. (1977) Anterior instability in the ankle joint following acute lateral sprain. Acta Radiological Diagnosis 18, 529-39.

Muwanga C. L., Quinton D. N., Sloan J. P., Gillies P. \& Dove A. F. (1986) A new treatment of stable lateral ligament injuries of the ankle joint. Injury (in press).

Rubin G. \& Witten M. (1960) The talar-tilt angle and fibular collateral ligaments. Fournal of Bone and foint Surgery 42A, 311-26.

Vargish T., Clarke W. R., Young R. A. \& Jensen A. (1983) The ankle injuries: indications for the selective use of X-rays. Injury 6, 507-12. 